\title{
Upper-thoracic versus lower-thoracic upper instrumented vertebra in adult spinal deformity patients undergoing fusion to the pelvis: surgical decision-making and patient outcomes
}

\author{
Alan H. Daniels, MD, ${ }^{1}$ Daniel B. C. Reid, MD, MPH, ${ }^{1}$ Wesley M. Durand, ScB, ${ }^{1}$ D. Kojo Hamilton, MD, ${ }^{2}$ \\ Peter G. Passias, MD, ${ }^{3}$ Han Jo Kim, MD, ${ }^{4}$ Themistocles S. Protopsaltis, MD, ${ }^{3}$ Virginie Lafage, $\mathrm{PhD},{ }^{4}$ \\ Justin S. Smith, MD, PhD, ${ }^{5}$ Christopher I. Shaffrey, MD, ${ }^{6}$ Munish Gupta, MD, ${ }^{7}$ Eric Klineberg, MD, ${ }^{8}$ \\ Frank Schwab, MD, ${ }^{4}$ Douglas Burton, MD, ${ }^{9}$ Shay Bess, MD, ${ }^{10}$ Christopher P. Ames, MD, ${ }^{11}$ \\ Robert A. Hart, MD, ${ }^{12}$ and the International Spine Study Group
}

\begin{abstract}
1Department of Orthopaedics, Warren Alpert Medical School of Brown University, Providence, Rhode Island; 2University of Pittsburgh Medical Center, Pittsburgh, Pennsylvania; ${ }^{3}$ Department of Orthopedics, NYU Langone Orthopedic Hospital, New York, New York; ${ }^{4}$ Hospital for Special Surgery, New York, New York; ${ }^{5}$ University of Virginia Health System, Charlottesville, Virginia; ${ }^{6}$ Duke University, Durham, North Carolina; ${ }^{7}$ Washington University, St. Louis, Missouri; ${ }^{8}$ University of California, Davis, Sacramento, California; 'University of Kansas Hospital, Kansas City, Kansas; ${ }^{10}$ Denver International Spine Center, Presbyterian/St. Luke's, Denver, Colorado; ${ }^{11}$ University of California, San Francisco, California; and ${ }^{12}$ Swedish Neuroscience Institute, Seattle, Washington
\end{abstract}

\begin{abstract}
OBJECTIVE Optimal patient selection for upper-thoracic (UT) versus lower-thoracic (LT) fusion during adult spinal deformity (ASD) correction is challenging. Radiographic and clinical outcomes following UT versus LT fusion remain incompletely understood. The purposes of this study were: 1) to evaluate demographic, radiographic, and surgical characteristics associated with choice of UT versus LT fusion endpoint; and 2) to evaluate differences in radiographic, clinical, and health-related quality of life (HRQOL) outcomes following UT versus LT fusion for ASD.
\end{abstract}

METHODS Retrospective review of a prospectively collected multicenter ASD database was performed. Patients with ASD who underwent fusion from the sacrum/ilium to the LT (T9-L1) or UT (T1-6) spine were compared for demographic, radiographic, and surgical characteristics. Outcomes including proximal junctional kyphosis (PJK), reoperation, rod fracture, pseudarthrosis, overall complications, 2-year change in alignment parameters, and 2-year HRQOL metrics (Lumbar Stiffness Disability Index, Scoliosis Research Society-22r questionnaire, Oswestry Disability Index) were compared after controlling for confounding factors via multivariate analysis.

RESULTS Three hundred three patients (169 LT, 134 UT) were evaluated. Independent predictors of UT fusion included greater thoracic kyphosis (odds ratio [OR] 0.97 per degree, $p=0.0098$ ), greater coronal Cobb angle (OR 1.06 per degree, $p<0.0001$ ), and performance of a 3-column osteotomy (3-CO; OR 2.39, $p=0.0351$ ). While associated with longer operative times (ratio 1.13, $p<0.0001$ ) and greater estimated blood loss (ratio 1.31, $p=0.0018$ ), UT fusions resulted in greater sagittal vertical axis improvement $(-59.5 \mathrm{vs}-41.0 \mathrm{~mm}, p=0.0035)$ and lower PJK rates (OR $0.49, p=0.0457)$. No significant differences in postoperative HRQOL measures, reoperation, or overall complication rates were detected between groups (all $p>0.1$ ).

CONCLUSIONS Greater deformity and need for 3-CO increased the likelihood of UT fusion. Despite longer operative times and greater blood loss, UT fusions resulted in better sagittal correction and lower 2-year PJK rates following surgery for ASD. While continued surveillance is necessary, this information may inform patient counseling and surgical decision-making. https://thejns.org/doi/abs/10.3171/2019.9.SPINE19557

KEYWORDS adult spinal deformity; scoliosis; upper thoracic; lower thoracic; upper instrumented vertebra; proximal junctional kyphosis; complications; outcomes

\footnotetext{
ABBREVIATIONS 3-CO = 3-column osteotomy; $\mathrm{ASA}=$ American Society of Anesthesiologists; $\mathrm{ASD}=$ adult spinal deformity; $\mathrm{CCI}=\mathrm{Charlson} \mathrm{Comorbidity} \mathrm{Index;} \mathrm{EBL}=$ estimated blood loss; HRQOL = health-related quality of life; ISSG = International Spine Study Group; LL = lumbar lordosis; LSDI = Lumbar Stiffness Disability Index; LT = lower thoracic; $\mathrm{ODI}=$ Oswestry Disability Index; $\mathrm{OR}=$ odds ratio; $\mathrm{PI}=$ pelvic incidence; $\mathrm{PJA}=$ proximal junction angle; $\mathrm{PJF}=$ proximal junctional failure; $\mathrm{PJK}=$ proximal junctional kyphosis; PT = pelvic tilt; SRS-22 $r$ = Scoliosis Research Society 22-r questionnaire; SVA = sagittal vertical axis; TK = thoracic kyphosis; UIV = upper instrumented vertebra; UT = upper thoracic.
}

SUBMITTED May 21, 2019. ACCEPTED September 30, 2019.

INCLUDE WHEN CITING Published online December 20, 2019; DOI: 10.3171/2019.9.SPINE19557. 
$\mathrm{S}$ URGERY for adult spinal deformity (ASD) has been shown to improve both radiographic spinal alignment parameters and health-related quality of life (HRQOL) measures in appropriately selected patients, $2,17,18,20$ although it has also been associated with a substantial complication rate. , $^{3,919,21,22}$ Some complications, such as proximal junctional kyphosis (PJK) and proximal junctional failure (PJF), have been previously associated with choice of upper instrumented vertebra (UIV) level. ${ }^{1,5,10,13}$ However, despite an early understanding of appropriate patient selection metrics as well as expected outcomes following ASD surgery, ${ }^{4,15,17,23,24}$ there is no clear consensus as to which patient demographic, radiographic, and clinical factors should be used to determine whether to fuse to the lower-thoracic (LT) versus upper-thoracic (UT) spine.

There is a need to more objectively determine the factors that are currently being used and those factors that should be used in the future to impact a surgeon's decision for a proximal endpoint. This study is a retrospective review of a prospectively collected multicenter database of patients with ASD designed to evaluate patient demographic, radiographic, and clinical variables associated with a surgeon's decision to fuse to the UT versus LT spine. Additionally, we evaluated patient outcomes in those undergoing fusion to the UT versus LT spine in terms of estimated blood loss (EBL), operative duration, perioperative complications, and 2-year HRQOL metrics.

\section{Methods \\ Patient Population}

A retrospective review of the prospectively collected multicenter International Spine Study Group (ISSG) database was performed. All patent care was provided by surgeons experienced in treating ASD, and IRB approval was obtained at all participating centers prior to data collection. For inclusion in the database, patients needed to meet at least one of the following criteria: age $\geq 18$ years old, diagnosis of adult degenerative or idiopathic scoliosis with curvature $\geq 20^{\circ}$, sagittal vertical axis (SVA) $>5$ $\mathrm{cm}$, pelvic tilt $(\mathrm{PT})>25^{\circ}$, or thoracic kyphosis $(\mathrm{TK})>$ $60^{\circ}$. Patients $\leq 18$ years old and those with a diagnosis of scoliosis other than degenerative or idiopathic (e.g., neuromuscular, congenital, paralytic, traumatic) were excluded from the database. The decision regarding whether to fuse to the UT versus LT spine was determined by individual surgeons based on clinical judgment.

\section{Data Collection}

Demographic, radiographic, and surgical characteristics, as well as any perioperative or postoperative complications, were collected on all included patients. Demographic variables included age, sex, comorbidities, Charlson Comorbidity Index (CCI), American Society of Anesthesiologists (ASA) score, BMI, and presence of osteoporosis. HRQOL factors included Lumbar Stiffness Disability Index (LSDI), Oswestry Disability Index (ODI), and Scoliosis Research Society 22-r questionnaire (SRS-22r). Surgical characteristics collected included EBL and operative duration. Each radiograph was reviewed by at least
2 readers. The accuracy and reliability of this approach has been previously validated. ${ }^{11}$ Radiographic measures included baseline and 2-year change in alignment parameters (SVA, pelvic incidence-lumbar lordosis [PI-LL], PT, TK) as well as incidence of PJK, PJF, pseudarthrosis, and rod fracture. PJK was defined as UIV to UIV+2 angle > $10^{\circ}$ or change in UIV-UIV+2 angle $>10^{\circ}$. PJF was defined by either proximal junction angle (PJA) $\geq 28.0^{\circ}$ and a change in PJA $\geq 21.6^{\circ}$ or listhesis (for LT UIV, listhesis and change $\geq 3 \mathrm{~mm}$; for UT UIV, listhesis and change $\geq$ $8 \mathrm{~mm}) .^{12}$

\section{Statistical Analysis}

UT and LT patients were compared for demographic, radiographic, and surgical characteristics. For bivariate analyses, the Wilcoxon rank-sum test and the chi-square test were used to compare continuous and categorical outcomes, respectively. Multivariate regression analysis was performed to evaluate independent demographic clinical and radiographic predictors of UT versus LT UIV fusion, as well as to compare clinical and radiographic outcomes following UT versus LT fusion. All regression analyses controlled for study site. Statistical significance was set a priori at $\mathrm{p}<0.05$.

\section{Results}

A total of 303 patients met the inclusion criteria. The baseline mean values were: SVA $81.1 \pm 73.0 \mathrm{~mm}$, PI-LL $20.9^{\circ} \pm 19.1^{\circ}$, PT $26.4^{\circ} \pm 9.8^{\circ}$, TK $-49.9^{\circ} \pm 17.6^{\circ}$, and coronal Cobb angle $40.5^{\circ} \pm 21.7^{\circ}$. The mean preoperative SRS score was $2.67 \pm 0.6$, ODI was $47.8 \pm 16.7$, and LSDI $35.8 \pm 16.7$. Mean operative duration was $474 \pm 169$ minutes and mean EBL was $2237 \pm 1703 \mathrm{ml}$ (Table 1). Of 303 patients analyzed, $169(55.8 \%)$ were fused to the LT and $134(44.2 \%)$ to the UT spine. In total, $25.1 \%$ of patients underwent 3-column osteotomy (3-CO), 28.7\% required reoperation, and $78.2 \%$ suffered a complication. The overall incidences of PJK, PJF, pseudarthrosis, and rod fracture were $29.0 \%, 20.5 \%, 23.2 \%$, and $18.2 \%$, respectively (Table 2).

Most patients fused to UT levels had a UIV at T3 (15.5\% of total patients) or T4 (19.5\%), while the majority of patients fused to LT levels had a UIV at T10 (36.6\%; Fig. 1).

At 2-year follow-up, mean values were: SVA $31.9 \pm$ $55.1 \mathrm{~mm}$, PI-LL $3.3^{\circ} \pm 14.9^{\circ}$, PT $22.6^{\circ} \pm 9.8^{\circ}$, TK $-59.4^{\circ}$ $\pm 16.3^{\circ}$, and coronal Cobb angle $20.8^{\circ} \pm 16.1^{\circ}$. Mean postoperative SRS score was $3.63 \pm 0.8$, ODI was $29.0 \pm 20.2$, and LSDI was $32.9 \pm 19.2$ (Table 1).

Bivariable analyses for differences between the UT and LT groups are presented in Supplemental Tables 1 and 2. On multivariate analysis, the following factors were predictive of decision to fuse to the UT spine: performance of 3-CO (odds ratio [OR] 2.39, $\mathrm{p}=0.0351$ ), greater magnitude of preoperative TK angle (OR 0.97 per degree, $\mathrm{p}=$ 0.0098 ), and greater maximum preoperative coronal Cobb angle (OR 1.06 per degree, $\mathrm{p}<0.0001$; Fig. 2); note that TK is expressed in negative degrees, thus this result indicates that a greater absolute magnitude of baseline TK is associated with increased likelihood of decision to fuse to 
TABLE 1. Descriptive statistics (continuous)

\begin{tabular}{|c|c|c|}
\hline Variable & Mean & SD \\
\hline Age & 62.7 & 9.2 \\
\hline BMI & 28.1 & 5.6 \\
\hline $\mathrm{CCl}$ & 1.9 & 1.7 \\
\hline \multicolumn{3}{|c|}{ Baseline alignment \& HRQOL } \\
\hline SVA (mm) & 81.1 & 73.0 \\
\hline PI-LL $\left(^{\circ}\right)$ & 20.9 & 19.1 \\
\hline $\mathrm{PT}\left({ }^{\circ}\right)$ & 26.4 & 9.8 \\
\hline $\mathrm{TK}\left({ }^{\circ}\right)$ & -49.9 & 17.6 \\
\hline Max Cobb angle $\left({ }^{\circ}\right)$ & 40.5 & 21.7 \\
\hline Total SRS score & 2.67 & 0.6 \\
\hline ODI & 47.8 & 16.7 \\
\hline LSDI & 35.8 & 16.7 \\
\hline \multicolumn{3}{|l|}{ 2-yr alignment \& HRQOL } \\
\hline SVA (mm) & 31.9 & 55.1 \\
\hline PI-LL $\left({ }^{\circ}\right)$ & 3.3 & 14.9 \\
\hline PT $\left({ }^{\circ}\right)$ & 22.6 & 9.8 \\
\hline $\mathrm{TK}\left({ }^{\circ}\right)$ & -59.4 & 16.3 \\
\hline Max Cobb angle $\left(^{\circ}\right)$ & 20.8 & 16.1 \\
\hline Total SRS score & 3.63 & 0.8 \\
\hline ODI & 29.0 & 20.2 \\
\hline LSDI & 32.9 & 19.2 \\
\hline \multicolumn{3}{|l|}{$\Delta$ (2-yr - baseline $)$} \\
\hline SVA (mm) & -49.2 & 66.5 \\
\hline PI-LL $\left(^{\circ}\right)$ & -17.6 & 16.7 \\
\hline $\mathrm{PT}\left({ }^{\circ}\right)$ & -3.8 & 8.1 \\
\hline $\mathrm{TK}\left({ }^{\circ}\right)$ & -9.5 & 14.2 \\
\hline Max Cobb angle $\left(^{\circ}\right)$ & -19.7 & 14.7 \\
\hline Total SRS & 0.97 & 0.7 \\
\hline ODI & -18.8 & 17.1 \\
\hline LSDI & -2.4 & 19.9 \\
\hline Op duration (mins) & 474 & 169 \\
\hline $\mathrm{EBL}(\mathrm{ml})$ & 2237 & 1703 \\
\hline
\end{tabular}

the UT spine. Nonsignificant positive ORs were also noted for female sex (OR 2.14, $\mathrm{p}=0.0572)$ and osteoporosis (OR 2.25, $\mathrm{p}=0.0712$; Fig. 2).

Bivariable analyses for the association of fusion to the UT spine with postoperative outcomes are presented in Supplemental Tables 3 and 4. Fusion to the UT spine was associated with a greater improvement in SVA $(-59.5$ vs $-41.0 \mathrm{~mm}, \mathrm{p}=0.0035$ ), greater operative duration (ratio $1.13, \mathrm{p}<0.0001$ ), greater EBL (ratio 1.31, $\mathrm{p}=0.0018$ ), and lower rates of PJK (OR 0.49, $\mathrm{p}=0.0457$ ). There was a nonsignificant trend toward lower rates of PJF (OR 0.54, $\mathrm{p}$ $=0.1384$ ) in patients with fusion to the UT spine. Among UT patients, the unadjusted incidence of PJK was 23.9\%, with $17.9 \%$ experiencing PJF. In comparison, among LT patients, the PJK rate was $33.1 \%$, with $22.5 \%$ experiencing PJF. There were no significant differences in postoperative HRQOL, PI-LL, PT, LSDI, PJF, pseudarthrosis, rod fracture, reoperation, or overall complication rates between UT and LT patients (all $\mathrm{p}>0.1$; Tables 3-5).
TABLE 2. Descriptive statistics (categorical)

\begin{tabular}{|c|c|c|}
\hline Variable & $\mathrm{N}$ & $\%$ \\
\hline \multicolumn{3}{|l|}{ UIV } \\
\hline LT & 169 & 55.8 \\
\hline UT & 134 & 44.2 \\
\hline \multicolumn{3}{|l|}{ Sex } \\
\hline Male & 63 & 20.8 \\
\hline Female & 240 & 79.2 \\
\hline \multicolumn{3}{|l|}{ ASA classification } \\
\hline Grade I-II & 160 & 52.8 \\
\hline Grade III-IV & 143 & 47.2 \\
\hline \multicolumn{3}{|l|}{ Osteoporosis } \\
\hline No & 255 & 84.2 \\
\hline Yes & 48 & 15.8 \\
\hline \multicolumn{3}{|l|}{$3-\mathrm{CO}$} \\
\hline No & 227 & 74.9 \\
\hline Yes & 76 & 25.1 \\
\hline \multicolumn{3}{|l|}{ Surgical approach } \\
\hline Posterior only & 206 & 68.0 \\
\hline Anterior only or anterior/posterior & 97 & 32.0 \\
\hline \multicolumn{3}{|l|}{ PJK } \\
\hline No & 215 & 71.0 \\
\hline Yes & 88 & 29.0 \\
\hline \multicolumn{3}{|l|}{ PJF } \\
\hline No & 241 & 79.5 \\
\hline Yes & 62 & 20.5 \\
\hline \multicolumn{3}{|l|}{ Pseudarthrosis* } \\
\hline No & 162 & 76.8 \\
\hline Yes & 49 & 23.2 \\
\hline \multicolumn{3}{|l|}{ Rod fracture } \\
\hline No & 248 & 81.9 \\
\hline Yes & 55 & 18.2 \\
\hline \multicolumn{3}{|l|}{ Reoperation } \\
\hline No & 216 & 71.3 \\
\hline Yes & 87 & 28.7 \\
\hline \multicolumn{3}{|l|}{ Any complication } \\
\hline No & 66 & 21.8 \\
\hline Yes & 237 & 78.2 \\
\hline
\end{tabular}

${ }^{*}$ Missing $=92$.

\section{Discussion}

Surgery for ASD requires sophisticated surgical decision-making to optimize patient outcomes and minimize complications. While the impact of fusion level on patient outcomes has been investigated, ${ }^{1,6-8,14,16}$ there remains no clear consensus regarding optimal UIV in individual patients. In practice, this choice continues to vary widely based upon patient, regional, institutional, and surgeon variables. In this investigation, we sought to objectively investigate the surgical decisions made by a group of ASD surgeons in relationship to patient preoperative demographic, clinical, and radiographic factors. Furthermore, 


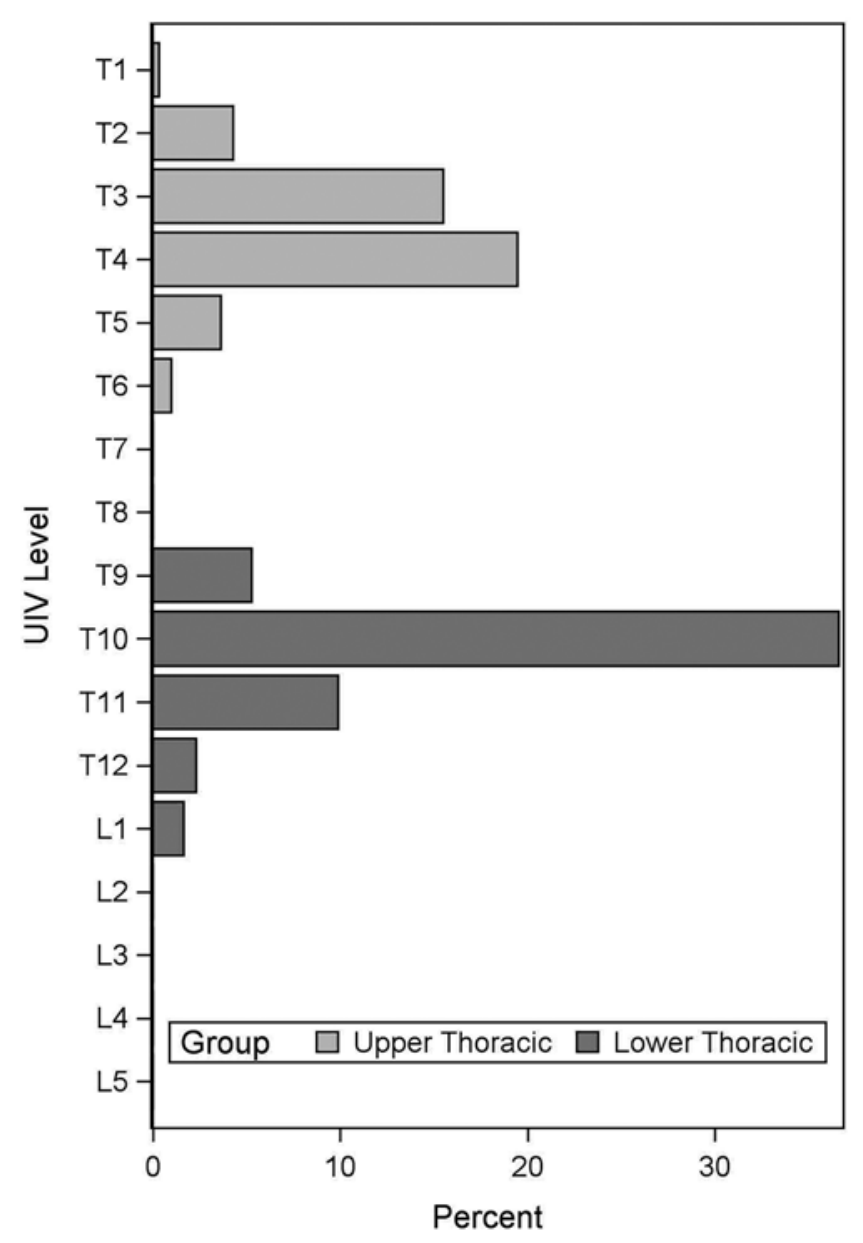

FIG. 1. Frequency distribution for UIV level among all patients.

we sought to evaluate the clinical and radiographic outcomes in those patients who underwent fusion to the UT compared to those with fusion to the LT spine. We found that surgeons more often chose UT endpoints when 3-COs were performed and when patients had worse baseline de- formity in terms of TK and coronal Cobb angle. While patients with fusion to the UT spine had higher mean EBL, longer operative durations, and larger SVA corrections, they had significantly lower rates of PJK. Furthermore, while not statistically significant, UT patients trended toward lower rates of PJF. There were no significant differences between groups in terms of pseudarthrosis, rod fracture, overall complications, revision surgery, or HRQOL improvement.

While the overall rates of both PJK and PJF were lower in patients with fusion to the UT spine, this difference was only statistically significant for PJK. After controlling for confounding variables, the ORs for PJK (0.49) and PJF (0.54) exhibited a similar trend toward decreased risk in UT patients. However, the absolute magnitude of the unadjusted difference between UT and LT rates was $9.3 \%$ for PJK versus only $4.6 \%$ for PJF. The lack of statistical significance for PJF may thus be related to limited power for detection of true differences in this relatively less common complication. Further surveillance is currently underway and data from larger cohorts of patients with ASD may elucidate this matter in the future.

This study revealed that the preoperative degree of radiographic TK is an important factor for surgeons deciding between UT and LT UIV and is likely related to both the desire to correct TK and to mitigate the risk of PJK, which is known to be higher in patients with elevated thoracic and thoracolumbar kyphosis. This is consistent with previous literature; an earlier review of 198 patients in the ISSG database published by Kim et al. in 2014 found that preoperative coronal and sagittal deformity were worse in those with fusion to the UT spine. ${ }^{8}$ Similarly, a 2012 retrospective review of 58 patients by O'Shaughnessy et al. found greater TK and coronal Cobb values in their UT fusion group. ${ }^{16}$ Further factors predicting UT fusion were performance of a 3-CO and larger coronal Cobb angle. Three-column osteotomies allow substantial sagittal deformity correction, and the potential for increased risk of PJK/PJF with large focal corrections may explain the choice of UT fusions in this group. Furthermore, the inherent spinal instability created during 3-COs may require

TABLE 3. Association between UIL and postoperative outcomes (radiographic and HRQOL)

\begin{tabular}{|c|c|c|c|c|c|}
\hline \multirow[b]{2}{*}{ Outcome* $^{*}$} & \multicolumn{2}{|c|}{ LT } & \multicolumn{2}{|c|}{ UT } & \multirow[b]{2}{*}{$p$ Value } \\
\hline & Mean & $95 \% \mathrm{Cl}$ & Mean & $95 \% \mathrm{Cl}$ & \\
\hline \multicolumn{6}{|l|}{ Alignment parameters } \\
\hline SVA (mm) & -41.0 & -48.4 to -33.6 & -59.5 & -68.1 to -51.0 & 0.0035 \\
\hline PI-LL $\left(^{\circ}\right)$ & -18.8 & -20.6 to -16.9 & -16.0 & -18.1 to -13.9 & 0.0813 \\
\hline PT $\left({ }^{\circ}\right)$ & -3.3 & -4.4 to -2.2 & -4.4 & -5.6 to -3.1 & 0.2724 \\
\hline $\mathrm{TK}\left({ }^{\circ}\right)$ & -9.6 & -11.4 to -7.7 & -9.4 & -11.6 to -7.3 & 0.9333 \\
\hline Max Cobb angle $\left(^{\circ}\right)$ & -20.1 & -21.8 to -18.3 & -19.3 & -21.3 to -17.3 & 0.5925 \\
\hline \multicolumn{6}{|l|}{ HRQOL } \\
\hline Total SRS & 0.9 & 0.8 to 1.0 & 1.0 & 0.9 to 1.1 & 0.4083 \\
\hline ODI & -17.7 & -20.6 to -14.8 & -20.2 & -23.5 to -16.9 & 0.3099 \\
\hline LSDI & -1.8 & -6.7 to 3.2 & -1.2 & -6.5 to 4.2 & 0.8753 \\
\hline
\end{tabular}

Boldface type indicates statistical significance.

${ }^{*} \Delta=2-y r-$ baseline. 


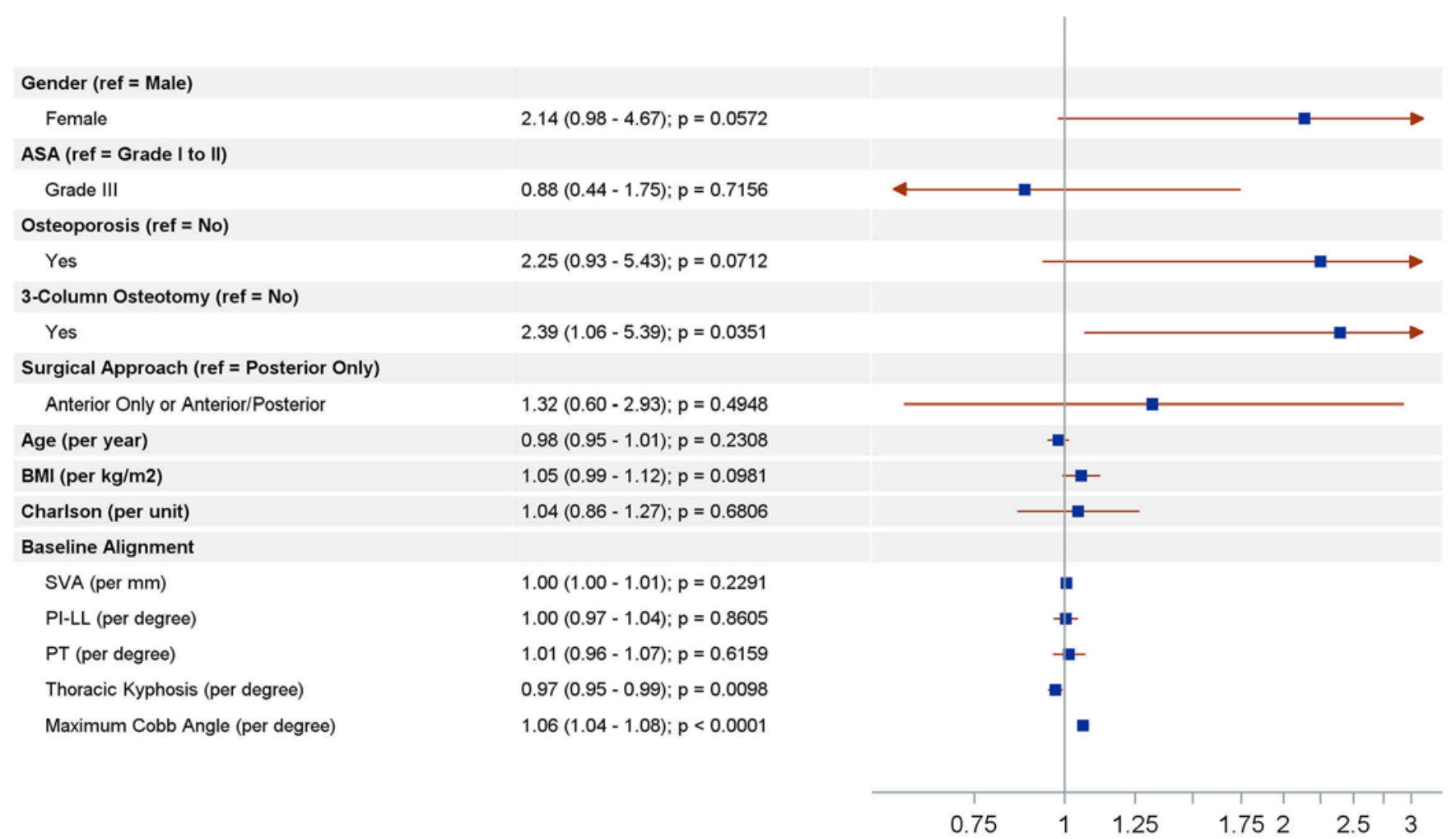

FIG. 2. Forest plot of predictors of UT UIV level. Note: as TK is expressed in negative degrees, this result indicates that a greater absolute magnitude of baseline TK is associated with increased likelihood of being a UT patient. Figure is available in color online only.

more extensive construct choices, including fusion to the UT spine. The association between preoperative coronal Cobb angle and UT fusion can be best explained by the necessity for constructs extending above the apex of the curve for deformity correction.

Consistent with prior studies, fusion to the UT level was associated with significantly increased operative time and EBL. ${ }^{7,16}$ Nonetheless, we found no significant difference in overall complication rates or HRQOL improvement, and therefore these factors may be of little clinical significance. For example, the change in LSDI from preoperative to 2-year postoperative was not significantly different for

TABLE 4. Association between UIL and postoperative outcomes (complications)

\begin{tabular}{lccc}
\hline \multicolumn{1}{c}{ Outcome } & OR & $95 \% \mathrm{Cl}$ & $\mathrm{p}$ Value \\
\hline PJK & 0.49 & 0.24 to 0.99 & $\mathbf{0 . 0 4 5 7}$ \\
\hline Reoperation & 1.11 & 0.58 to 2.11 & 0.7532 \\
\hline Any complication & 1.12 & 0.56 to 2.27 & 0.7483 \\
\hline PJF & 0.54 & 0.24 to 1.22 & 0.1384 \\
\hline Pseudarthrosis & 0.96 & 0.33 to 2.79 & 0.9412 \\
\hline Rod fracture & 1.55 & 0.71 to 3.41 & 0.2731 \\
\hline
\end{tabular}

Boldface type indicates statistical significance.
UT versus LT patients; therefore, concerns about a more extensive surgery and more functional stiffness and complications in UT patients may not be warranted.

Our study is one of the largest to date comparing UT versus LT UIV in patients with ASD. Strengths of this study include the relatively large number of patients included as well as our use of the well-established prospectively collected ISSG database. Potential limitations include those inherent to any retrospective study design; specifically, there is risk of selection bias. No randomization took place, and whether to fuse to the LT or UT spine was determined through a shared decision-making process between patient and surgeon. While our statistical analysis controlled for potential confounders, it is possible that there are confounding variables that were either not anticipated or not collected. Additionally, while we can evaluate the patient demographic and clinical factors that

TABLE 5. Association between UIL and postoperative outcomes (surgical outcomes)

\begin{tabular}{lccc}
\hline Outcome & Ratio & $95 \% \mathrm{Cl}$ & $\mathrm{p}$ Value \\
\hline Op duration & 1.13 & 1.06 to 1.19 & $<0.0001$ \\
\hline EBL & 1.31 & 1.11 to 1.55 & $\mathbf{0 . 0 0 1 8}$ \\
\hline
\end{tabular}

Boldface type indicates statistical significance. 
make surgeons more or less likely to choose a UT UIV, we cannot determine the reason for them doing so in each case.

\section{Conclusions}

Factors associated with the decision to fuse to the UT spine in patients with ASD included performance of a 3-CO, larger TK, and larger coronal Cobb angle. UT patients had a significantly lower rate of radiographic PJK at 2-year follow-up, but reoperation rates and overall complication rates, including pseudarthrosis and rod fracture, were not significantly different. The decision regarding UIV level among spine surgeons may currently be guided by the anticipated risk of PJK versus operative risk and the ability to perform larger corrections with UT fusions. While our study provides evidence that the incidence of radiographic PJK is likely lower in those with fusion to the UT spine, we failed to detect a difference in clinical outcomes, including reoperation, HRQOL, lumbar stiffnessrelated disability, or overall complication rates. Further surveillance for complications including PJK, PJF, pseudarthrosis, and rod fracture, as well as outcomes-based research comparing UT versus LT fusion level, is still necessary before any firm treatment recommendations can be made.

\section{Acknowledgments}

IRB approval was obtained at all participating institutions for collection and analysis of patient data. This study was funded by the ISSG Foundation (ISSGF).

\section{References}

1. Annis P, Lawrence BD, Spiker WR, Zhang Y, Chen W, Daubs $\mathrm{MD}$, et al: Predictive factors for acute proximal junctional failure after adult deformity surgery with upper instrumented vertebrae in the thoracolumbar spine. Evid Based Spine Care J 5:160-162, 2014

2. Bae J, Theologis AA, Strom R, Tay B, Burch S, Berven S, et al: Comparative analysis of 3 surgical strategies for adult spinal deformity with mild to moderate sagittal imbalance. J Neurosurg Spine 28:40-49, 2018

3. Bhagat S, Vozar V, Lutchman L, Crawford RJ, Rai AS: Morbidity and mortality in adult spinal deformity surgery: Norwich Spinal Unit experience. Eur Spine J 22 (Suppl 1):S42-S46, 2013

4. Carreon LY, Glassman SD, Shaffrey CI, Fehlings MG, Dahl $\mathrm{B}$, Ames CP, et al: Predictors of health-related quality-of-life after complex adult spinal deformity surgery: a Scoli-RISK-1 secondary analysis. Spine Deform 5:139-144, 2017

5. Cho SK, Shin JI, Kim YJ: Proximal junctional kyphosis following adult spinal deformity surgery. Eur Spine J 23:27262736, 2014

6. Ha Y, Maruo K, Racine L, Schairer WW, Hu SS, Deviren V, et al: Proximal junctional kyphosis and clinical outcomes in adult spinal deformity surgery with fusion from the thoracic spine to the sacrum: a comparison of proximal and distal upper instrumented vertebrae. J Neurosurg Spine 19:360-369, 2013

7. Kang X, Dong L, Yang T, Wang Z, Huang G, Chen X: Clinical and radiographic outcomes of upper thoracic versus lower thoracic upper instrumented vertebrae for adult scoliosis: a meta-analysis. Braz J Med Biol Res 51:e6651, 2018

8. Kim HJ, Boachie-Adjei O, Shaffrey CI, Schwab F, Lafage
V, Bess S, et al: Upper thoracic versus lower thoracic upper instrumented vertebrae endpoints have similar outcomes and complications in adult scoliosis. Spine (Phila Pa 1976) 39:E795-E799, 2014

9. Kim HJ, Iyer S, Zebala LP, Kelly MP, Sciubba D, Protopsaltis TS, et al: Perioperative neurologic complications in adult spinal deformity surgery. Spine (Phila Pa 1976) 42:420-427, 2017

10. Kim HJ, Lenke LG, Shaffrey CI, Van Alstyne EM, Skelly AC: Proximal junctional kyphosis as a distinct form of adjacent segment pathology after spinal deformity surgery: a systematic review. Spine (Phila Pa 1976) 37 (22 Suppl):S144S164, 2012

11. Lafage R, Ferrero E, Henry JK, Challier V, Diebo B, Liabaud $\mathrm{B}$, et al: Validation of a new computer-assisted tool to measure spino-pelvic parameters. Spine J 15:2493-2502, 2015

12. Lafage R, Schwab FJ, Bess S, Burton DC, Ames CP, Hart $\mathrm{RA}$, et al: Redefining radiographic thresholds for junctional kyphosis pathologies. Spine J 15 (10 Suppl):S216, 2015

13. Luo M, Wang P, Wang W, Shen M, Xu G, Xia L: Upper thoracic versus lower thoracic as site of upper instrumented vertebrae for long fusion surgery in adult spinal deformity: a meta-analysis of proximal junctional kyphosis. World Neurosurg 102:200-208, 2017

14. Maruo K, Ha Y, Inoue S, Samuel S, Okada E, Hu SS, et al: Predictive factors for proximal junctional kyphosis in long fusions to the sacrum in adult spinal deformity. Spine (Phila Pa 1976) 38:E1469-E1476, 2013

15. Miller EK, Neuman BJ, Jain A, Daniels AH, Ailon T, Sciubba DM, et al: An assessment of frailty as a tool for risk stratification in adult spinal deformity surgery. Neurosurg Focus 43(6):E3, 2017

16. O'Shaughnessy BA, Bridwell KH, Lenke LG, Cho W, Baldus $\mathrm{C}$, Chang MS, et al: Does a long-fusion "T3-sacrum" portend a worse outcome than a short-fusion "T10-sacrum" in primary surgery for adult scoliosis? Spine (Phila Pa 1976) 37:884-890, 2012

17. Reid DBC, Daniels AH, Ailon T, Miller E, Sciubba DM, Smith JS, et al: Frailty and health-related quality of life improvement following adult spinal deformity surgery. World Neurosurg 112:e548-e554, 2018

18. Riley MS, Bridwell KH, Lenke LG, Dalton J, Kelly MP: Health-related quality of life outcomes in complex adult spinal deformity surgery. J Neurosurg Spine 28:194-200, 2018

19. Smith JS, Klineberg E, Lafage V, Shaffrey CI, Schwab F, Lafage R, et al: Prospective multicenter assessment of perioperative and minimum 2-year postoperative complication rates associated with adult spinal deformity surgery. J Neurosurg Spine 25:1-14, 2016

20. Smith JS, Lafage V, Shaffrey CI, Schwab F, Lafage R, Hostin R, et al: Outcomes of operative and nonoperative treatment for adult spinal deformity: a prospective, multicenter, propensity-matched cohort assessment with minimum 2-year follow-up. Neurosurgery 78:851-861, 2016

21. Soroceanu A, Burton DC, Oren JH, Smith JS, Hostin R, Shaffrey CI, et al: Medical complications after adult spinal deformity surgery: incidence, risk factors, and clinical impact. Spine (Phila Pa 1976) 41:1718-1723, 2016

22. Soroceanu A, Diebo BG, Burton D, Smith JS, Deviren V, Shaffrey C, et al: Radiographical and implant-related complications in adult spinal deformity surgery: incidence, patient risk factors, and impact on health-related quality of life. Spine (Phila Pa 1976) 40:1414-1421, 2015

23. Yagi M, Fujita N, Okada E, Tsuji O, Nagoshi N, Asazuma $\mathrm{T}$, et al: Fine-tuning the predictive model for proximal junctional failure in surgically treated patients with adult spinal deformity. Spine (Phila Pa 1976) 43:767-773, 2018

24. Yoshida G, Hasegawa T, Yamato Y, Kobayashi S, Shin O, Banno T, et al: Predicting perioperative complications in 
adult spinal deformity surgery using a simple sliding scale. Spine (Phila Pa 1976) 43:562-570, 2018

\section{Disclosures}

Dr. Daniels reports a nonfinancial personal relationship with Stryker, Orthofix, Spineart, EOS, Springer, and Southern Spine. Dr. Passias reports being a consultant for Medicrea and SpineWave, and being on the Scientific Advisory Board, receiving speaking/teaching arrangements, and receiving grants from Terumo BCT, Zimmer Biomet, and the Cervical Spine Research Society. Dr. Lafage reports direct stock ownership in Nemaris Inc.; being a consultant for Globus Medical; receiving royalties from NuVasive; speaking/teaching arrangements with DePuy Synthes Spine/The Permanente Medical Group; serving on the Executive Committee of ISSG; and serving on the editorial board of the European Spine Journal. Dr. Smith reports being a consultant for Zimmer Biomet, K2M/Stryker, NuVasive, AlloSource, and Cerapedics; receiving royalties from Zimmer Biomet and NuVasive; clinical or research support for this study from DePuy Synthes; support of non-study-related clinical or research effort from DePuy Synthes and AOSpine; and fellowship support from NREF and AOSpine. Dr. Shaffrey reports being a consultant for NuVasive, Medtronic, Eos, and Siemens; direct stock ownership in NuVasive; and being a patent holder for NuVasive, Medtronic, and Zimmer Biomet. Dr. Gupta reports being a consultant for DePuy and Medtronic; direct stock ownership in $\mathrm{J} \& \mathrm{~J}$ and $\mathrm{P}$ \& $\mathrm{G}$; receiving royalties, serving on the advisory board, and travel arrangements from DePuy; receiving royalties from Innomed; receiving stock options from perForm Biologics; receiving travel arrangements from Alphatec, SRS, and Medtronic; being on the advisory board of Medtronic; and grants from AOSpine and OMeGA paid directly to the institution for a fellowship. Dr. Klineberg reports being a consultant for DePuy, Stryker, and Medicrea; receiving honoraria from K2M and AOSpine; and receiving a fellowship grant from AOSpine. Dr. Schwab reports being a consultant for Globus Medical, Zimmer Biomet, MSD, and K2M; direct stock ownership in Nemaris Inc; support of nonstudy-related clinical or research effort from DePuy, K2M, NuVasive, Medtronic, Globus, AlloSource, Orthofix, and SIBone; and speaking/teaching arrangements from Globus Medical, Zimmer Biomet, MSD, and K2M. Dr. Burton reports receiving clinical or research support for this study from Pfizer and DePuy; being a patent holder for DePuy; and being a consultant for Bioventus. Dr. Bess reports being a consultant for K2/Stryker; being a patent holder for K2/Stryker; clinical or research support for this study from ISSGF; and support of non-study-related clinical or research effort from ISSGF. Dr. Ames reports being a consultant for DePuy Synthes, Medtronic, Stryker, Medicrea, K2M, and Biomet Zimmer; receiving royalties from Stryker, Biomet Zimmer Spine, DePuy Synthes, NuVasive, Next Orthosurgical, K2M, and Medicrea; receiving research support from Titan Spine, DePuy Synthes, and ISSG; being on the editorial board of Operative Neurosurgery; receiving grant funding from SRS; being on the Executive Committee of ISSG; and serving as the director of Global Spinal Analytics. Dr. Hart reports being a consultant for Globus, Medtronic, DePuy Synthes, and Orthofix; and receiving royalties from ISSLS.

\section{Author Contributions}

Conception and design: Daniels, Durand. Acquisition of data: Reid, Daniels, Hamilton, Passias, Kim, Protopsaltis, Lafage, Smith, Gupta, Klineberg, Schwab, Burton, Bess, Ames, Hart. Analysis and interpretation of data: Reid, Daniels, Durand, Shaffrey. Drafting the article: Reid. Critically revising the article: all authors. Reviewed submitted version of manuscript: Reid. Approved the final version of the manuscript on behalf of all authors: Reid. Statistical analysis: Durand. Study supervision: Daniels.

\section{Supplemental Information}

\section{Online-Only Content}

Supplemental material is available with the online version of the article.

Supplemental Tables 1-4. https://thejns.org/doi/suppl/10.3171/ 2019.9.SPINE19557.

\section{Correspondence}

Daniel B. C. Reid: Warren Alpert Medical School of Brown University, Providence, RI. daniel_b_reid@brown.edu. 